\title{
La Poesía de Gastón Figueira
}

A NALIZAR la producción de un poeta es tarea grata, aunque A de mucha responsabilidad, porque para juzgarla hay que empezar siendo poeta.

Mi juicio crítico estará destinado a apreciar con honradez la abundante obra de Gastón Figueira, poeta auténtico que desde el Uruguay canta a los niños de América, con característica dulzura lírica. Su quid divinum nace a flor de labios. Su alma destila perfumes que producen encantamiento.

En cada poesía suya está gráficamente impregnada la magnificencia de América, con sus panoramas imponentes, con sus bellezas inmaculadas. Sus versos constituyen un alarde de honestidad y sabiduría. Son perlas cargadas de esencias.

La poesía "figueirana" tiene un sello característico: unidad, ritmo y sensibilidad. En cada verso hallamos la personalidad del artista.

La producción de Gastón Figueira ensambla, a mi ver, condiciones y cualidades relevantes, que apoyan su prestigio, ya universal.

Soy tu hijo, ;oh América mía!:

Como tú, generoso seré.

Como tú, daré siempre al hermano

la palabra que calme su sed.

Para el poeta "el mundo es hermoso y en él toda angustia se puede olvidar". Mas para ello hay que sobreponerse al dolor y a la tribulación que producen los vaivenes de la vida.

En "Invocación", Figueira expresa su estado de ánimo, diciendo:

Vamos adelante

en la noche llena 
de gritos de anhelo, de angustia llameante.

Que sea serena

mi palabra, y lleve tan clara dulzura

que, oyéndola, todos

puedan olvidar su sed y amargura,

y ya para siempre sientan en su vida

$y$ en su alma de fe estremecida.

el fulgor vibrante

del inmenso Arcano. 1

Pero después de la nostalgia se registra una notable mutación en el poeta. En "Vida" engrana su sentimiento y su lirismo:

\author{
Vida del poeta, \\ vida de Jesús: \\ Las dos anhelando \\ of rendar su luz \\ desde la negrura \\ torva de la cruz. 2
}

Figueira nació para ser poeta. Joven aún, ofrecía a la crítica su primer libro de poemas, mereciendo el más rotundo éxito. Obtenido este triunfo, Figueira prosiguió trabajando intensa e incansablemente. Cuenta en la actualidad con más de treinta libros, muchos de los cuales han sido traducidos a vários idiomas, hecho elocuentísimo del gran valor de sus trabajos.

Para respaldar mi juicio, mencionaré muy especialmente las opiniones que sobre sus obras vertieron escritores americanos.

La poetisa uruguaya Emma Santandreu Morales, al analizar las poesías de Figueira, ha dicho que "son un códice de sabiduría geográfica y armoniosa, todo dibujado de signos geológicos y humanos. Indice iluminado que nos evoca desde la edad del cobre rojo a la civilización suntuaria del inmenso mundo americano. Voz de voces que a través de los siglos resuena en el cambiante color de las mitologías indias, en la piedra y en la raza, y que supo escuchar el poeta, acolchada de silencio su sandalia de peregrino infatigable". Gabriela Mistral, al referirse al libro Para los niños de América, dijo: "El es, para mí, una especie de casa familiar. Pensamos lo mismo sobre el patio común de los niños latinoamericanos, que llamamos América del Sur. Los hemos hecho cantar casi a la vez."

Gastón Figueira es ante todo "el poeta del fervor americanista, el cantor de los niños de América, de las naciones de todo el Continen- 
te", según el acertado juicio de la escritora nombrada en primer término.

La poesía de Figueira llega al lector, por su fondo y por su lirismo, como un "inextinguible tesoro de bondad y de belleza" que ilumina el "altar vasto y milagroso del Arte y del Ensueño".

Sin mengua el bardo expresa lo que siente, haciéndolo con honradez y castidad:

\author{
La lluvia es el llanto \\ de los niños muertos. \\ que sólo el dolor \\ en la tierra vieron. \\ La lluvia es el llanto \\ de los niños huérfanos, \\ que en la noche tiemblan \\ de frío y de miedo. \\ La lluvia es el llanto \\ de los niños ciegos. 3
}

Esta "Canción", profundamente humana, da la pauta del entrañable amor que Figueira tiene a los niños:



Este amigo armonioso de los niños de América da con bondad desbordante todo cuanto puede exhalar su noble espíritu. Cada verso está saturado de ternura infantil:

$$
\begin{aligned}
& \text {.. No hay en el mundo nada } \\
& \text {-para aquel que sufre sin fin-, } \\
& \text { nada más dulce que mirar los juegos } \\
& \text { de los niños en un jardin... }
\end{aligned}
$$

Figueira encuentra en los niños paz y alegría, amor y sinceridad. Jugando espiritualmente con ellos olvida por un momento su dolor, al que convierte en "verbos de fe, dulzura y amor". Auténtico americano, el poeta uruguayo preconiza y aspira el triunfo de la democracia para bien de la Humanidad. Su fe es límpida y veraz. El poeta 
propugna con su poesía candorosa el afianzamiento de las instituciones. Su palabra fervorosa y cálida los une, los hace más hermanos a todos los pueblos de América. Su canto sinfónico, profundo y sublime, trasunta las inquietudes del poeta:

Bellos países americanos:

ised siempre hermanos, buenos hermanos!

Hermanos todos en el amor,

en el trabajo y en el valor.

"Niño indio" es un magistral poema que nace y concluye exornado de amor purísimo, olor a bosques y a aguas de manantiales vírgenes, donde pugna el americanismo castizo de este insigne artista:

Niño indio, de los llanos:

conmigo ven a jugar.

Todos los niños de América

siempre nos hemos de amat.

Niño indio, de los bosques:

conmigo ven a cantar.

Todos los niños de América

haremos un solo hogar.

Niño indio, niño indio:

yo te enseñaré a leet.

Todos los nifios de América

tenemos sed de aprender.

pues la ignorancia esclaviza

y el saber nos da el poder.

Niño indio, niño indio, conmigo ven a jugar.

Todos los niños de América

siempre nos hemos de amar. 4

El lirismo de Figueira emociona. Sus poesías se leen con instintiva simpatía. El poeta canta las bellezas de su tierra con graficidad y soltura lorquianas. Probablemente porque su espíritu abreva en las fértiles e inagotables fuentes de América, tan majestuosas como las del Guadalquivir.

Paso a paso Figueira recuerda a sus amigos, los niños de América. Para ello derrama a raudales su bondad espiritual, en consejos profundos y vigorosos: 
Que sea vuestra alma como

las flores del naranjal,

leves, blancas, puras, llenas

de claridad.

Donde más demuestra su entrañable amor, es en "El poeta y los niños":

Venid, niños, venid, niños, todos a mi alrededor.

¡Ah, no sabéis cuán inmenso

por vosotros es mi amor:

Venid, niños, entonad

vuestras canciones hermosas.

Danzad alegres, cual danzan

las abejas con las rosas.

i Ah, venid todos, jugad

con los libros de esta mesa,

donde para mí pasaron

tantas boras de tristeza!

Llenad con vuestros dibujos,

llenad con vuestra alegría

estos papeles que guardan

versos de melancolía.

Venid, niños, repetidme

del Ratón Pérez el cuento.

Mirad cómo al escucharos

estoy de nuevo contento.

Vosotros dais a mi alma

una beatitud inmensa.

Vosotros sois para mí

la más bella recompensa.

Venid, niños, venid, niños, todos a mi alrededor,

a traerme una esperanza,

a embellecer mi dolor! 5

Son, en realidad, los niños quienes alegran a Figueira, nacido para poetizar sus alegrías. Para el poeta, los niños "vienen al mundo a traer la esperanza, a darnos la alegría. Son ángeles-poetas que en- 
noblecen al hombre con sólo una sonrisa". Pide a Dios que guarde para ellos "toda la miel del mundo", porque los niños son los únicos que nos hacen amar la vida.

Gastón Figueira es un auténtico hijo de América, que hace honor a su lúcida estirpe. Bien dice el poeta que "América es el templo del Dios de la Alegría", por su límpida trayectoria a través de los años.

El americanismo de Figueira se extiende a todos los pueblos. Es un admirador de México, la hermosa y heroica ciudad azteca.

Una poesía magistral nos pone en contacto directo con la fisonomía de ese pueblo abnegado, que vive en un estado de constante superación. La aguda observación del poeta ha llegado a descubrir sus costumbres y a sacudir el alma de sus pobladores:

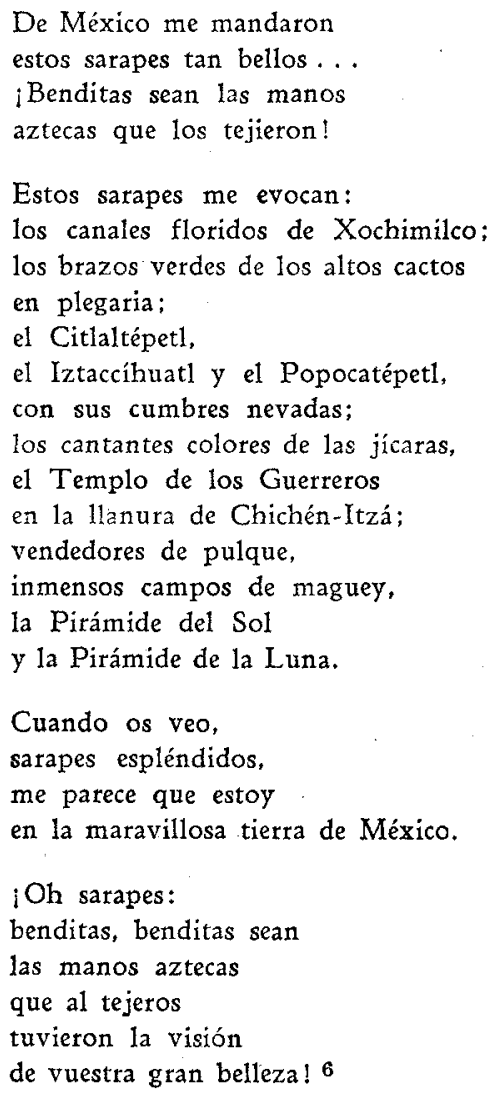


Figueira, con esa fluidez propia, proverbial ya en él, canta a su México amado y admirado. Canta incansablemente a los paises de América, porque los ama y porque por ellos siente singular deleite espiritual; en sus poesías deja su lúcido y admirable deseo de acercarlos, de unirlos, de hacer que se amen mutuamente para consolidar la América real, la América que siente palpitar el anhelo de la verdadera democracia, donde haya justicia y libertad para todos. A eso aspira Figueira con su poesía. Sus versos encierran pensamientos puros y límpidos que merecen ser grabados en placas de oro.

Este poeta nos pone nuevamente en contacto con México. Es en una danza tradicional de los indígenas otomíes, llamados Xitas, que viven en San Luis de las Peras. La poesía se intitula "La virgen y las fieras" y dice así:

La niña vive en el valle

y el valle quiere a la niña.

Sus arroyuelos le cantan

historias de maravilla.

El sol le hace. con flores,

guirnaldas multicolores.

La niña vive en el valle

$y$ el valle quiere a la niña.

Como es tan pura y alegre, como es $\tan$ comprensiva, también las fieras la quieren, $y$ a ella acuden sumisas las fieras innumerables de la gran selva vecina. [Ah, la gran selva vecina: ¿Cómo parece profunda, misteriosa, pensativa!

¿Qué encerrará su verdor?

La selva tienta a la niña.

La selva le dice: ":Ven!"

"¿Quédate!" - el valle replica.

"QQuédate!" - replica el valle.

"Aqui está la dulce paz...

Allí, el misterio mortal."

Pero una tarde, la niña

no pudo más resistir

al hechizo de la selva,

a su verde voz febril. 


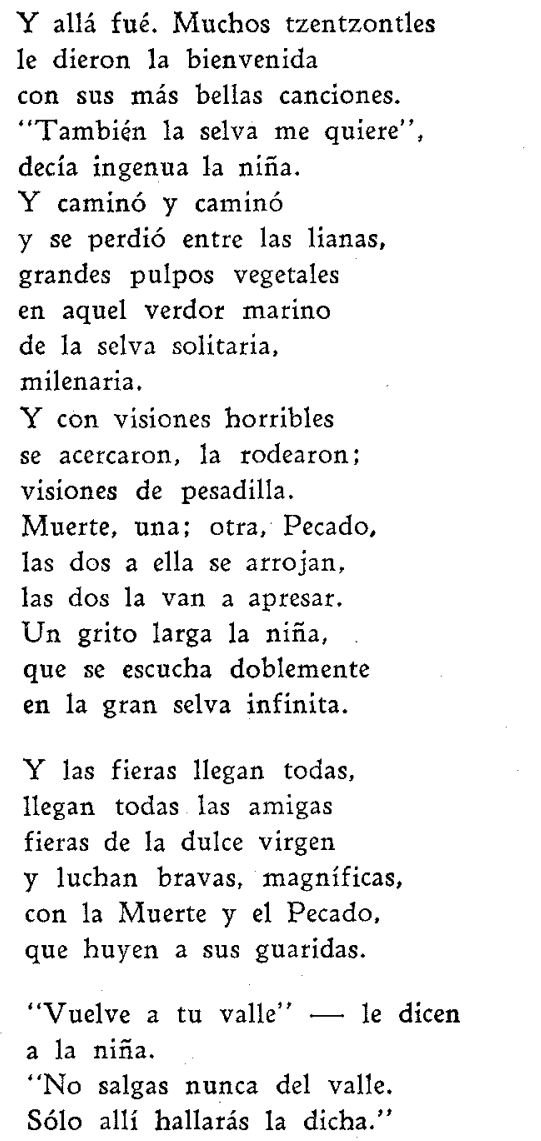

Ahora es otra ciudad de América la que se presenta ante nosotros a través de la inspiración de Figueira: Río de Janeiro, la ciudad de hechiceria, "que millares de esplendideces encierra", porque es la tierra "donde verdean las florestas tropicales" y donde se yerguen triunfales los rascacielos blancos:

Ciudad que a todos of renda

la alegría de vivir.

de su cielo bajo el clato

sonreir...

¡Oh corazón que la vida

ha puesto amargo y sombrio!: 
Si tú quieres ser feliz anda a Río, anda a Río, que millares de esplendideces encierra, anda a Río, la ciudad más hermosa de la tierta. 7

En la hermosa ciudad carioca, tradicional por sus plátanos y papagayos, se presenta nuevamente el poeta, en "Bahía de Gtranabara", cantando:

\author{
Cada mañana, \\ cuando abro de mi cuarto la ventana \\ y te miro, magnífica bahía, \\ mi alma es pequeña para mi alegría... \\ Nada sé de mis penas, \\ mis luchas, mis anhelos. \\ Sólo sé que te tengo \\ frente a mí como el don más bello de los cielos! \\ Sólo sé que en mis ojos y en mi alma tú sonties, \\ mientras el Sol, con labios de oro joven, te besa. \\ Con sólo contemplar tu inmenso rostro azul, \\ sé que la vida, toda la vida, es belleza...
}

La Tierra, siempre joven, es igual a una novia que sonríe con una dulcedumbre auroral y todas las mañanas se casa con el Sol... Tú eres, ;oh Bahía!, su sortija nupcial ...8

Su poesía es una llovizna de azahares, que perfuman las tierras de la ciudad del porvenir. Dice el poeta que cada vez que mira a Río, la encuentra más hermosa, más rica, más reluciente, más grande, más majestuosa:

Río de Janeiro, qqué alegres

y qué claras son tus calles!

Tu muchedumbre no es triste como en las otras ciudades.

Tu muchedumbre sontíe

y es siempre gentil, amable. 
Poesía exquisita que fluye de "uno de los más grandes poetas latinoamericanos", como afirma Paul Rogers, o de un "artista puro", al decir del malograelo Romain Rolland.

La belleza de Río se agiganta, haciéndose más inmensa y emotiva en el verbo de Figueira:

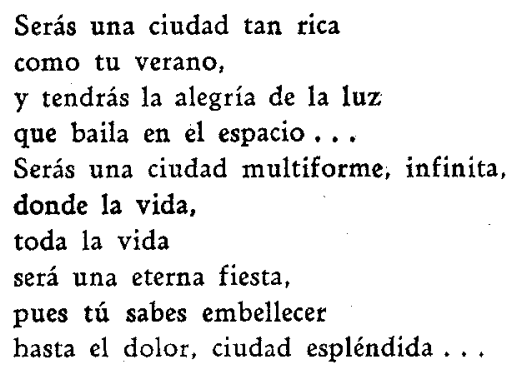

Figueira debe apartarse de su Brasil admirado y admirable, a quien le ofrendó la dulzura de su lira y le descubrió sus bellezas latentes; le descifró sus cuitas, le exhumó sus leyendas y le cantó a sus pájaros y a sus flores:

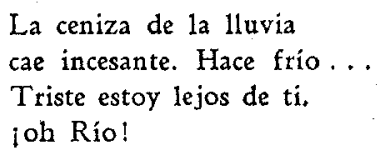

Y agrega :

En vano los libros quieren mi pesadumbre aliviar.

Con la cabeza en las manos. sólo en ti quiero pensar...

Y termina su evocación, diciendo:

Agujas de lluvia cosen evocaciones nostálgicas... Triste estoy lejos de ti, ¿Río, Rio, ciudad mágica! . .

Entremos ahora a analizar las páginas de Las baladas, de cuyo interior exhala una dulzura poética que embarga nuestro espíritu. "Amadlo todo en la tierra, porque todo, siendo amado, tiene bondad 
y belleza", dice Figueira. En este amor profundo es justamente donde radica el triunfo de este estilista americano.

Escuchemos su "Balada de la dicha":

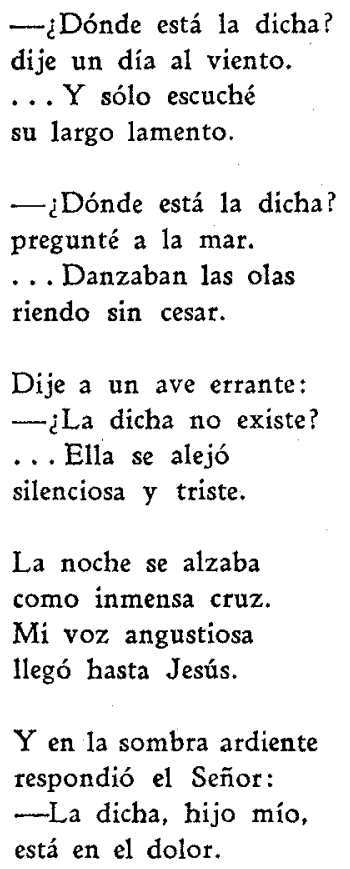

En Figueira "fluyen las estrofas como hilos de miel". Dice el poeta: "No importa que te acerques, soledad del desencanto. No he de verte porque llevo el corazón en la mano, y la sonrisa en los ojos y la balada en los labios."

Lo que comprendió Figueira, es que de "este loco y ávido errar por el mundo", una sola verdad llegó a comprender: "que bajo la eterna ceniza del Tiempo, tanto da gozar como padecer."

En la "Balada de la resignación" el poeta trasmite acertadamente sia lúcido pensamiento:

Oculté en mi carne, con hondo fervor.

las espinas negras que me dió el dolor.

Mis sienes no sangran, mi boca no implora; no hay llanto que enturbie mis ojos ahora. 
(Y adentro... jeste enorme dolor que crepita;

esta mordedura tenaz, infinita!)

No hay llanto que enturbie mis ojos ahora:

mis sienes no sangran, mi boca no implora.

El panamericanismo de Gastón Figueira está sólidamente representado en esta magistral poesía:

Creo en ti, Panamérica,

porque creo en la humana fraternidad

y en el amanecer de una Nueva Humanidad.

Te veo así, gran Arca de Noé, en borrascoso mundo,

nimbada de un fulgor profundo.

Creo en $t i$, Panamérica bendita,

toda llena de sol, toda llena de vida, toda llena de gracia,

llena toda de paz y libertad.

Creo en ti, Panamérica, creo en tu inmensidad, porque creo en la Democracia.

Su americanidad es pura como el alma de la raza india.

Para Figueira, el verdadero sentido de la americanidad es volver en defensa del indio, reivindicándolo, porque en él, verdaderamente, está la raíz de nuestra existencia. Devolverle el lugar que le corresponde, es obra que debe realizar el panamericanismo. Cumplida esta misión, estaremos en condiciones de hablar con énfasis de americanidad.

En "Altiplano andino", Figueira ha dejado nuevamente la graficidad de su ferviente americanismo. Así dice:

¿Qué gloria comparable a la tuya, indio,

cuando la tierra de toda América,

virgen y pura,

era tu tierra,

la de tu libertad,

la de tu feliz inocencia!

Indio,

se alza una nueva democracia

$y$ en ella 
hay amor, comprensión y respeto

para ti, para tus hijos, para tu compañera.

Indio,

ven con nosotros.

Entra a la ronda

de la Nueva América.

Manos amigas hacia ti se extienden.

¡Estréchalas!

Aquí se conduele Figueira del derrotero incierto y de la postergación en que se halla actualmente el indio en América, que ha sido despojado de su tierra, de su arte maravilloso, abandonándolo para que él solo sea quien se defienda de las arbitrariedades y de los abusos, de las ofensas y de las burlas. Por eso Figueira clama con voz preñada de amor americanista por que se reivindique al indio. En "Indio", el artífice traza con mano escultórica la verdadera situación del primer poblador de América:

Modelaste el cántaro con tierra tuya, indio lejanísimo,

indio que estás quizás dando vida a algún árbol.

Hoy, en un museo de gran ciudad,

frente a mis ojos el cántaro está.

y pienso que esta obra de arte,

tan bella en su ingenuidad,

en su estética primitiva y perfecta,

me habla de ti y de tu raza.

$Y$ me dice:

- "Nietos del que nos creó

cerca de ti están.

Harapientos,

cansados,

sin un pedazo de tierra,

sin ojos para ver la aurora,

esa mágica aurora de la América tropical.

¡Y fué su raza dueña de todo este prodigio

y sabía cantar y gustaba bailar

ebria de la alegría de los bosques sin fin,

los lagos y las cumbres, la gran luz virginal!

¿No hay en esta América

lugar

para el indio?" 
$Y$ yo respondo:

-.'Sí. Lo hay.

Hombres de América,

indios, blancos, mestizos,

están luchando con lealtad,

para que nuestro hermano primitivo

tenga su casa limpia,

su jardin, su corral.

Hombres de América,

para todo aborigen crearán

la vida digna,

la vida activa,

la fecunda vida.

$Y$ entonces,

sólo entonces,

será auténtica fiesta

nuestra americanidad."

Orgánicamente hemos llegado, no al descubrimiento, sino a un exacto conocimiento de un gran poeta americano.

Gastón Figueira es un esclarecido pintor de la naturaleza. Su poesía perdurará por su impecable concepción. Leerlo es ratificar mi aserto.

$$
\begin{aligned}
& \text { Fermín A. Anzalaz, } \\
& \text { La Rioja, Argentina. }
\end{aligned}
$$

\section{NOTAS}

1 Crucifixión de luz, 1944.

2 Ibid.

3 Ibid.

4 Para los niños de América.

5 Ibid.

6 Ibid.

7 Rio de Janeito, ciudad de hechicetia.

8 Ibid. 